in vivo $35: 2107-2114(2021)$

doi:10.21873/invivo.12480

\title{
Complex Modulating Effects of Dietary Calcium Intake on Obese Mice
}

\author{
MAIKO TAKAHASHI ${ }^{1}$, TAKAHIRO HAMOYA ${ }^{1,2}$, TAKUMI NARITA ${ }^{1,2}$, GEN FUJII $^{3}$, YUKARI TOTSUKA $^{4}$, \\ MASAHITO HAGIO ${ }^{5}$, KOSUKE TASHIRO ${ }^{6}$, MASAMI KOMIYA ${ }^{1}$ and MICHIHIRO MUTOH ${ }^{1,2}$ \\ ${ }^{1}$ Division of Prevention, Center for Public Health Sciences, National Cancer Center, Tokyo, Japan; \\ ${ }^{2}$ Department of Molecular-Targeting Prevention, Graduate School of Medical Science, \\ Kyoto Prefectural University of Medicine, Kyoto, Japan; \\ ${ }^{3}$ Central Radioisotope Division, National Cancer Center Research, Tokyo, Japan; \\ ${ }^{4}$ Department of Animal Experimentation, National Cancer Center Research Institute, Tokyo, Japan; \\ ${ }^{5}$ Chemistry Division, Kanagawa Prefectural Institute of Public Health, Chigasaki, Japan; \\ ${ }^{6}$ Department of Bioscience and Biotechnology, Faculty of Agriculture, Kyushuu University, Fukuoka, Japan
}

\begin{abstract}
Background/Aim: Overweight and obesity are risk factors for chronic diseases. Dietary calcium has been reported to exert anti-obesity effects. However, the complex modulating effects of calcium intake on obese mice have not been clarified. Materials and Methods: The effects of calcium intake on body weight/visceral fat mass were examined in the obese mouse model, $K K-A^{y}$. Results: Body weight gain decreased in mice fed a diet containing 0.4 to $3.2 \%$ calcium at the age of 11 and 13 weeks, but not at 12 weeks after normalization for food intake. Calcium intake also decreased serum insulin levels and increased the amount of feces excreted. Fecal deoxycholate levels were lower in the highcalcium group than in the normal diet control group. Furthermore, the ratio of the deoxycholate-producing microbiome in feces decreased. Conclusion: Dietary calcium has anti-obesity effects in obese $K K-A^{y}$ mice. Inhibition of insulin production and an increased amount of feces excreted with calcium intake may affect body weight.
\end{abstract}

The prevalence of overweight and obesity is continually increasing. Worldwide estimates in 2016 showed that 1.97 billion adults and more than 338 million children and

This article is freely accessible online.

Correspondence to: Michihiro Mutoh, MD, Ph.D., Department of Molecular-Targeting Prevention, Graduate School of Medical Science, Kyoto Prefectural University of Medicine, KawaramachiHirokoji, Kamigyo-ku, Kyoto 602-8566, Japan. Tel: +81 752515339, Fax: +81 752410792, e-mail: mimutoh@koto.kpu-m.ac.jp

Key Words: Dietary calcium intake, visceral fat volume, KK- $A^{\mathrm{y}}$ mice, insulin, deoxycholic acid. adolescents were overweight or obese (1). Excess weight and obesity are risk factors for a number of chronic diseases, such as cardiovascular disease, diabetes and cancer (2-4). In the case of cancer, obesity has been identified as a risk factor for colon cancer (4). We previously reported that obese KK$A^{y}$ mice were susceptible to azoxymethane-induced colorectal carcinogenesis (5), and the visceral fat volume (VFV) in humans correlated more strongly with the prevalence of colorectal adenomas than the visceral fat area (VFA) on CT (6). The relationship between cancer and obesity may be explained by the effects of insulin resistance, imbalance in adipocytokines, dyslipidemia, and induction of inflammation (7).

Excess body fat has been implicated in the development of chronic diseases and reduces life expectancy. Excess of energy uptake from food and drink is stored as fat in adipose tissue, but may be reduced by a healthy diet and physical activities. Thus, overweight and obesity may be reversed by healthy lifestyle habits. Calcium has been shown to exert anti-obesity effects $(8,9)$. A previous study reported that body mass index (BMI) in black men was 3.3 points lower in a high-calcium intake group $(458 \mathrm{mg} / 1,000 \mathrm{kcal}$ energy) than in a lowcalcium intake group $(214 \mathrm{mg} / 1,000 \mathrm{kcal}$ energy) (7).

$\mathrm{KK}-A^{y}$ mice have been established by cross-mating KK mice, a mouse model of diabetes mellitus type 2 , with C57BL/6J- $A^{y}$ mice $(10,11)$, which carry the Agouti gene $\left(A^{y}\right)$. These mice exhibit severe hyperphagia, hyperinsulinemia, and dyslipidemia, and are a good animal model for investigating the relationship between obesity and cancer (5).

In the present study, we examined the complex effects of dietary calcium intake on body weight gain and visceral fat mass in obese $\mathrm{KK}-A^{y}$ mice, and found calcium-induced changes in serum insulin levels, the amount of feces, and the ratio of intestinal bacteria. 


\section{Materials and Methods}

Cells. Calcium carbonate and calcium chloride dihydrate were purchased from WAKO Pure Chemical Industries (Osaka, Japan). HIT-T15 cells, hamster islet of Langerhans beta cells, were purchased from the American Type Culture Collection (Manassas, VA, USA). This cell line was maintained in RPMI1640 supplemented with $10 \%$ heat-inactivated fetal bovine serum (FBS; HyClone Laboratories Inc., Logan, UT, USA) at $37^{\circ} \mathrm{C}$ in a $5 \% \mathrm{CO}_{2}$ humidified atmosphere.

Animal experiments. Female KK-Ay mice and AIN-76A diet were purchased from CLEA Japan Inc. (Shizuoka, Japan). Mice (n=5-6) were housed in plastic cages with sterilized softwood chips as bedding in a barrier-sustained animal room maintained at $24 \pm 2{ }^{\circ} \mathrm{C}$ and $55 \%$ humidity under a 12 -h light/dark cycle. Mice were fed an AIN-76A powdered basal control diet (containing $0.4 \%$ calcium) and test diets were mixed with calcium carbonate (WAKO Pure Chemical Industries, Osaka, Japan) to give total calcium levels of $0.8,1.6$ and $3.2 \%$. Five or six female KK- $A^{y}$ mice aged 5 weeks were given 0.4 to $3.2 \%$ calcium for 8 weeks. Food and water were available ad libitum. Mice were observed daily for clinical symptoms and mortality. Body weight and food consumption were measured weekly and feces were collected from the age of 9 to 13 weeks. At 13 weeks of age, all animals were euthanized by isoflurane overdose for tissue collection and blood samples were collected from abdominal veins. Visceral fat from the uterus and surrounding fat was removed and weighed before being fixed in $10 \%$ buffered formalin. Subcutaneous fat was collected from the backs of mice. All experiments were performed according to the "Guidelines for Animal Experiments in the National Cancer Center" and were approved by the Institutional Ethics Review Committee for Animal Experimentation of the National Cancer Center (T17091). The animal protocol was designed to minimize pain and discomfort. Mice were acclimatized to laboratory conditions for more than two weeks prior to experimentation.

Measurement of serum lipid, blood glucose, and insulin levels in mice. Blood samples from KK- $A^{y}$ mice were centrifuged at 3,000 $\mathrm{rpm}$ for $15 \mathrm{~min}$ to obtain serum that were stored at $-20^{\circ} \mathrm{C}$. Serum samples were used to measure triglyceride, total cholesterol, and blood glucose levels using the DRI-CHEM system (Fuji Film, Tokyo, Japan) and Accu-Chek ST meter (Roche, Basel, Switzerland). Insulin levels in the serum and the cell-cultured medium were assessed using mouse insulin ELISA kits (Morinaga Institute of Biological Science, Inc., Kanagawa, Japan and Mercodia, Uppsala, Sweden, respectively). HIT-T15 cells were seeded on 6 -well plates $\left(7.5 \times 10^{5}\right.$ cells/well). After a 24 -h pre-incubation, cells were cultured in medium supplemented with $0.50-2.00 \mathrm{mM}$ (total 0.92-2.42 $\mathrm{mM}$ ) calcium chloride (WAKO Pure Chemical Industries) for $48 \mathrm{~h}$. Cells were then washed with PBS and cultured for a further $2 \mathrm{~h}$. The cell supernatant was collected and subjected to measurements of insulin levels.

Measurement of fecal deoxycholate (DCA) levels. DCA was extracted with ethanol from a $100-\mathrm{mg}$ fecal sample prepared by mixing the feces of 4 mice (12). Extracted samples were assessed by LC-QTOF mass analyses using a Shimadzu Prominence LC system interfaced with a Triple TOF6600 mass spectrometer (SCIEX, Framingham, MA, USA) in the product ion (PI) mode. The column temperature was set to $40^{\circ} \mathrm{C}$. Solvent A was acetonitrilewater (20:80) containing $10 \mathrm{mM}$ ammonium acetate and solvent B was acetonitrile-water (80:20) containing $10 \mathrm{mM}$ ammonium acetate. Chromatographic separation was performed using a previously reported procedure (12) with the following minor modifications: $0-5 \mathrm{~min}, 5 \% \mathrm{~B} ; 5-15 \mathrm{~min}$, linear gradient to $15 \% \mathrm{~B}$; 15-20 min, linear gradient to $25 \%$ B; 20-25 min, $75 \%$ B. Samples were separated on SynergiTM Fusion-RP (particle size of $2.5 \mu \mathrm{m}$, $2.0 \times 100 \mathrm{~mm}$; Phenomenex, Torrance, CA, USA) and eluted at a flow rate of $0.4 \mathrm{ml} / \mathrm{min}$. Mass spectral analyses in the PI mode were performed in the negative ion mode with nitrogen as the nebulizing gas. The ion source temperature was $120^{\circ} \mathrm{C}$ and the desolvation gas temperature was $400^{\circ} \mathrm{C}$. Nitrogen gas was used as the desolvation gas $(700 \mathrm{l} / \mathrm{h})$ and cone gas $(35 \mathrm{l} / \mathrm{h})$, and argon was used to provide a collision cell pressure of $1.5 \times 10^{-3}$ mbar. Regarding the internal standard, nordeoxycholic acid (NDCA) was monitored with $\mathrm{m} / \mathrm{z}$ 377.3 and DCA with $\mathrm{m} / \mathrm{z} 391.3$, respectively, with a cone voltage of $35 \mathrm{~V}$ and collision energy of $10 \mathrm{eV}$.

Microbiome analysis. Samples were collected from the feces of mice at 9 and 13 weeks in the $0.4 \%$ (control) and $3.2 \%$ calcium diet groups. We did not have a metabolic cage, so we used a regular plastic cage in the present experiment. The stool was collected together with the chips the day after the cage was replaced, and all the stool were manually removed. To investigate the microbiome in feces, next generation sequencing library preparations and Illumina MiSeq sequencing were conducted by GENEWIZ, Inc. (Suzhou, PR China). A 16s rRNA data analysis was performed to assess the ratio of the bacteria in the microbiome.

Statistical analysis. All statistical analyses were performed using Student's $t$-tests, except for insulin in HIT-T15 cells, which was assessed using Dunnett's test. Differences were considered to be significant at $* p<0.05$ and $* * p<0.01$.

\section{Results}

The high-calcium diet effect on body weight gain normalized for food intake by mice. To reveal the relationship between dietary calcium intake and VFV, obese KK- $A^{y}$ mice were fed a high-calcium diet. No significant differences were observed in body weight between mice fed a diet with calcium doses of $0.8,1.6$, or $3.2 \%$ and $0.4 \%$ (control diet), as shown in Figure 1A. However, the calcium diet slightly increased food intake in a dose-dependent manner, except for the last two weeks of the experimental period (Figure 1B). Thus, we normalized body weight gain by food intake (Table I). Normalized body weight gain was significantly decreased by the high-calcium diet (more than $1.6 \%$ calcium) at the age of 11 and 13 weeks ( $p<0.05 v s$. the control group). Of note, the results obtained at the age of 11 weeks showed that body weight increased by $0.066 \mathrm{~g}$ per $1 \mathrm{~g}$ food intake in the control group and $0.032 \mathrm{~g}$ per $1 \mathrm{~g}$ food intake in the $3.2 \%$ calcium diet group.

Table II shows mean body and fat weights in each group. Although the high-calcium diet did not significantly reduce visceral or subcutaneous fat weights, the visceral fat weight $v$. 

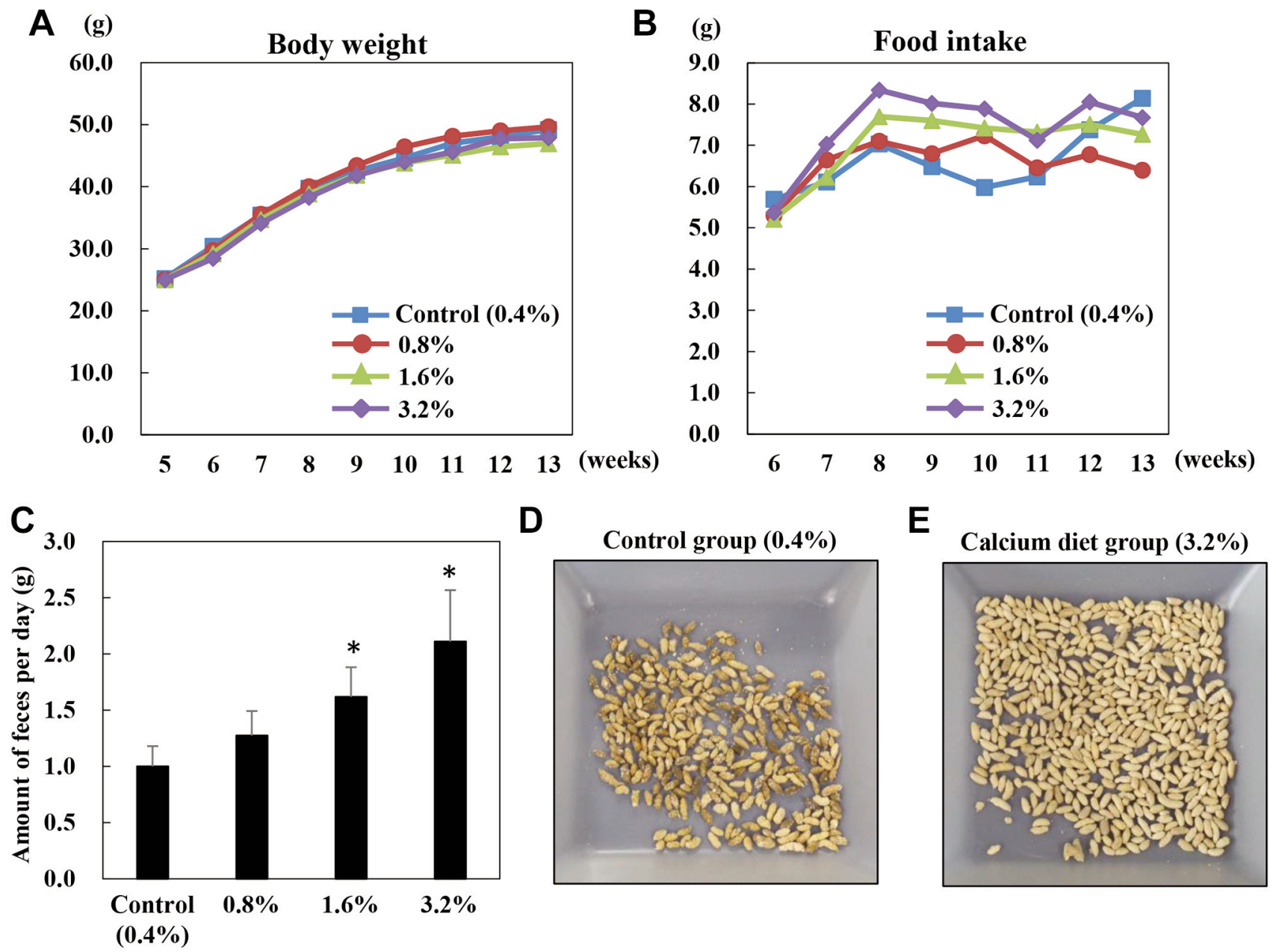

Figure 1. Changes of body weight, food intake and weight of feces during the experimental period in KK-A ${ }^{y}$ mice fed the high-calcium diet. (A-B) $K K-A^{y}$ mice were divided into the following 4 groups: mice fed a diet containing $0.4 \%$ (control diet), $0.8 \%, 1.6 \%$, or $3.2 \%$ calcium. The body weight of each mouse and food intake were measured once a week. Changes in body weight (A) and food intake (B) during the ages of 5-13 weeks are shown. (C-E) The mean weights of feces per day in the indicated groups from the age of 9 to 13 weeks are shown. The amount of feces was expressed as grams per mouse per day in each group. Data are means $\pm S D$, ${ }^{*} p<0.05$ vs. the control diet group. Feces were collected every day, and photographs were taken for the control group $(D ; n=5$ mouse) and $3.2 \%$ group $(E ; n=6$ mouse $)$ at the age of 13 weeks.

Table I. Calculated body weight gain normalized by food intake amount in the groups treated with different calcium doses.

\begin{tabular}{lllllllll}
\hline & $6 \mathrm{wks}$ & $7 \mathrm{wks}$ & $8 \mathrm{wks}$ & $9 \mathrm{wks}$ & $10 \mathrm{wks}$ & 11 wks & $12 w k s$ & 13 wks \\
\hline Control $(0.4 \%)$ & 0.104 & 0.127 & 0.089 & 0.057 & 0.057 & 0.066 & 0.019 & 0.020 \\
$0.8 \%$ & 0.127 & 0.125 & 0.089 & 0.072 & 0.059 & 0.038 & 0.018 & 0.011 \\
$1.6 \%$ & 0.115 & 0.126 & 0.076 & 0.058 & 0.037 & $0.025^{*}$ & 0.025 & 0.008 \\
$3.2 \%$ & 0.092 & 0.115 & 0.071 & 0.063 & 0.040 & $0.032^{*}$ & 0.038 & $0.002^{*}$ \\
\hline
\end{tabular}

Data represent mean values. *Significantly different from the control diet group at $p<0.05$.

subcutaneous fat weight ratio (V/S) was significantly decreased ( $p<0.05 v s$. the control group). The $\mathrm{V} / \mathrm{S}$ ratio was calculated in the present study because we have previously reported that the $\mathrm{KK}-A^{y}$ mouse accumulates more visceral fat than subcutaneous fat (5). Visceral fat/Body weight (\%) and Subcutaneous fat/Body weight $(\%)$ ratios were further calculated and statistically analyzed. As a result, Visceral fat/Body weight (\%) was not changed by calcium administration. Subcutaneous fat/Body 
Table II. Amount of body and fat weight in the group treated with different calcium doses.

\begin{tabular}{lcccc}
\hline & Control (0.4\%) & $0.8 \%$ & $1.6 \%$ & $3.2 \%$ \\
\hline Body weight (g) at the start & $25.2 \pm 0.74$ & $25.0 \pm 0.87$ & $25.0 \pm 1.07$ & $25.0 \pm 1.13$ \\
Body weight (g) at the end & $49.3 \pm 3.01$ & $49.9 \pm 3.54$ & $46.8 \pm 2.61$ & $47.9 \pm 2.77$ \\
Increase of body weight (g) & $24.1 \pm 2.51$ & $24.8 \pm 3.17$ & $21.8 \pm 1.67$ & $22.9 \pm 3.12$ \\
Visceral fat weight (g) & $6.26 \pm 0.81$ & $6.63 \pm 0.60$ & $12.4 \pm 1.85$ & $6.14 \pm 0.63$ \\
Visceral fat/Body weight (\%) & $12.7 \pm 1.27$ & $13.3 \pm 0.73$ & $2.22 \pm 0.33$ & $12.8 \pm 0.81$ \\
Subcutaneous fat weight (g) & $1.77 \pm 0.51$ & $2.34 \pm 0.40$ & $4.7 \pm 0.61$ & $2.38 \pm 0.50$ \\
Subcutaneous fat/Body weight (\%) & $3.6 \pm 1.08$ & $4.7 \pm 0.73$ & $263.6 \pm 49.1 *$ & $4.9 \pm 0.88^{*}$ \\
V/S (\%) & $385.9 \pm 137.0$ & $288.9 \pm 45.6$ & $0.41 \pm 0.05$ & $262.2 \pm 27.0 *$ \\
Brown adipose tissue (g) & $0.49 \pm 0.10$ & $0.4 \pm 0.08$ & $0.4 \pm 0.84$ \\
\hline
\end{tabular}

Data represent mean $\pm \mathrm{SD}$. V/S=Visceral fat weight/Subcutaneous weight $\times 100$. *Significantly different from the control diet group at $p<0.05$.

A

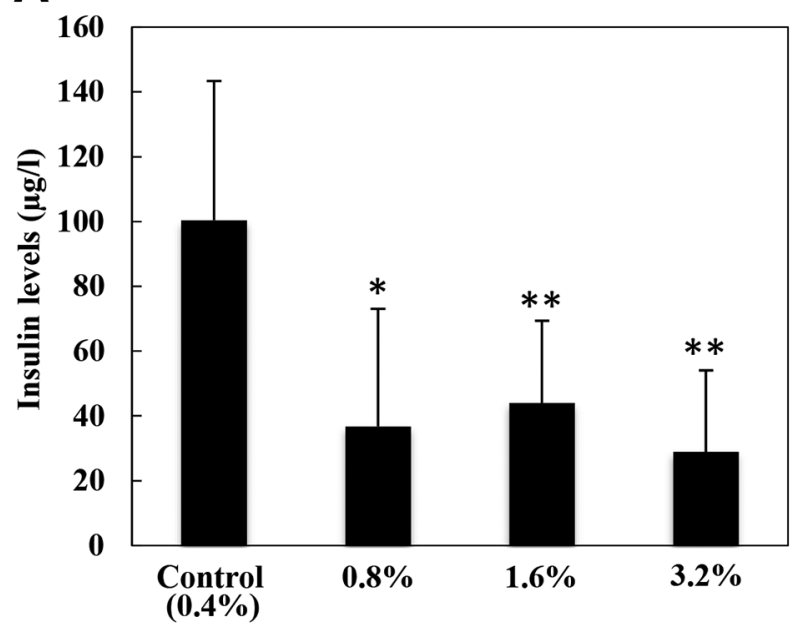

B

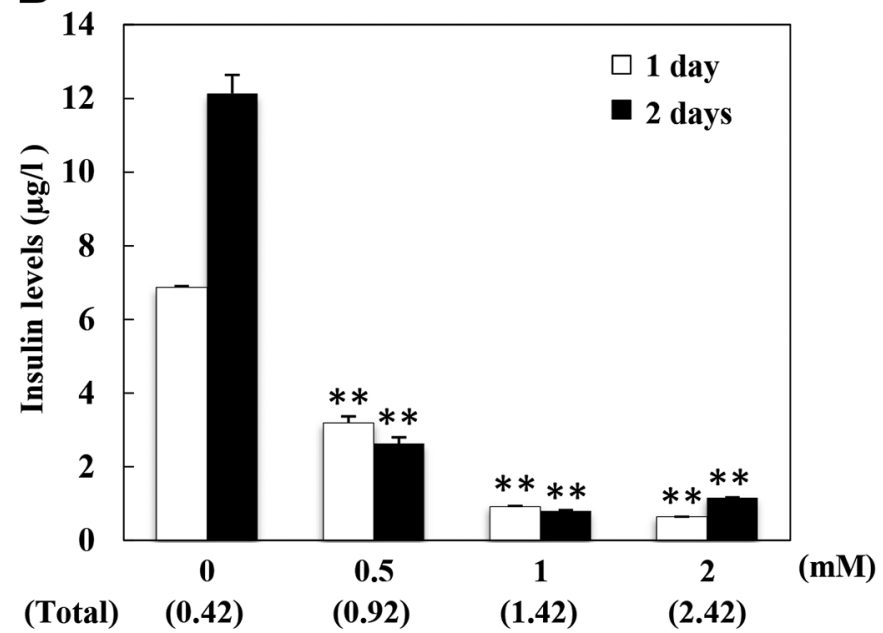

Figure 2. Insulin secretion under high-calcium conditions. (A) Mouse serum was obtained at the end of the experiment from the groups fed 0.4 (control diet), 0.8, 1.6, and 3.2\% calcium, and insulin levels were measured using an ELISA kit. Data are means $\pm S D, n=5-6$ (mice). ${ }^{*} p<0.05$ and $* * p<0.01$, vs. the control diet group. (B) HIT-T15 cells were treated with the indicated dose of calcium chloride $(0.92-2.42 \mathrm{mM})$ for one and two days. The levels of insulin in the cell medium were measured using an ELISA kit. Data are means $\pm S D, * * p<0.01$, vs. without calcium chloride.

weight $(\%)$ was significantly increased by administration of $3.2 \%$ calcium $(p=0.04)$.

Brown adipose tissue weight was not affected by the highcalcium diet. Furthermore, the liver weight slightly decreased with increases in the calcium dose $(2.40 \pm 0.61,2.45 \pm 0.46$, $2.20 \pm 0.22$, and $2.14 \pm 0.65 \mathrm{~g}$ in the $0.4,0.8,1.6$, and $3.2 \%$ groups, respectively). However, no improvements were observed in fatty liver (HE staining data not shown).

The high-calcium diet increased the excretion of feces. Feces were collected and the amount of feces excreted per day was calculated. The calcium diet increased the amount of feces excreted per day in a dose-dependent manner, as shown in Figure $1 \mathrm{C}$. The amount of feces collected at 13 weeks was 2.18 -fold greater in the $3.2 \%$ calcium diet group than in the control group (Data not shown). The color of feces at 13 weeks had a whiter appearance in the $3.2 \%$ calcium diet group than in the control group (Figure 1D and E).

Insulin levels were significantly reduced by the high-calcium diet. To elucidate the mechanisms underlying calcium intakeinduced reduction in $\mathrm{VFV}$, serum insulin levels were measured in $\mathrm{KK}-A^{y}$ mice fed the calcium diet. Serum insulin levels were examined because insulin plays an important role in the storage of triglycerides in adipocytes. The results showed that the $1.6 \%$ high-calcium diet significantly reduced serum insulin levels to $44.0 \%$ of those in the control diet group. The $3.2 \%$ high-calcium diet significantly reduced serum insulin levels to $28.9 \%$ of those in the control diet group, as shown in Figure 2A. On the other hand, totalcholesterol was increased by the $3.2 \%$ high-calcium diet, but glucose levels were slightly increased (Table III). 
Table III. Change of the serum lipids and blood glucose levels during the experimental period in KK-Ay mice.

\begin{tabular}{lcccc}
\hline & No. of mice & Triglycerides $(\mathrm{mg} / \mathrm{dl})$ & Total-cholesterol $(\mathrm{mg} / \mathrm{dl})$ & Blood $)$ \\
\hline Control $(0.4 \%)$ & 5 & $833.2 \pm 142.2$ & $114.4 \pm 15.4$ & $399.2 \pm 89.6$ \\
$0.8 \%$ & 5 & $592.8 \pm 133.2$ & $136.0 \pm 25.0$ & $415.4 \pm 82.3$ \\
$1.6 \%$ & 5 & $876.0 \pm 217.3$ & $118.4 \pm 18.9$ & $504.2 \pm 113.9$ \\
$3.2 \%$ & 6 & $947.3 \pm 237.7$ & $151.3 \pm 18.1$ & $522.8 \pm 165.5$ \\
\hline
\end{tabular}

Data represent mean $\pm \mathrm{SD}$.

Figure 2B shows the effects of calcium on insulin secretion by HIT-T15 cells. Insulin secretion was decreased in a calcium dose-dependent manner. On the first day after the addition of calcium, $2.42 \mathrm{mM}$ calcium reduced insulin secretion to $9.3 \%$ of that secreted by untreated control cells. On the second day of the treatment, marked reductions in insulin secretion were observed between untreated control and calcium-treated cells.

Changes in DCA levels and the microflora in feces by the high-calcium treatment. Obesity is associated with increases in the number of DCA-producing bacteria (16). Therefore, we measured fecal DCA levels in feces. Fecal DCA levels were lower in the high-calcium group than in the normal diet control group $(265.0,256.3,19.4$, and $18.1 \mathrm{pmol} / \mathrm{ml} \mathrm{DCA}$ in the $0.4,0.8,1.6$, and $3.2 \%$ calcium groups, respectively). To clarify why DCA levels decreased, we examined the ratio of intestinal bacteria. The results obtained showed that the ratio of several intestinal bacteria, such as Clostridiaceae, which produce DCA, were reduced in the intestinal flora (Figure 3 ).

\section{Discussion}

In the present study, we demonstrated that the complex effects of calcium intake on the obese mice. Body weight did not decrease following calcium intake. Body weight gain per food intake decreased at the age of 11 and 13 weeks but not at 12 weeks. Subcutaneous fat weight was increased by calcium intake. This may be partly explained by increasing defecation and decreasing insulin secretion in $\mathrm{KK}-A^{y}$ mice fed high calcium diet. Furthermore, insulin secretion by Langerhans beta cells treated with calcium decreased. The reductions observed in fecal DCA levels may be attributed to changes in the intestinal flora.

In the present study, food intake increased in a calcium dose-dependent manner during the experimental period. Thus, we normalized gains in body weight by food intake and observed a significant difference in the high-calcium group. We calculated the $\mathrm{V} / \mathrm{S}$ ratio when animals were euthanized and found a significant decrease. In metabolic syndrome, visceral fat rather than subcutaneous fat plays an important role in the pathology. In addition, $\mathrm{KK}-A^{y}$ mice gain more visceral fat than subcutaneous fat. Therefore, we calculated the change in visceral to subcutaneous fat ratio. Previous studies have reported that physical activity reduced visceral fat more than subcutaneous fat $(13,14)$. Therefore, similar to the effects of physical activity, visceral fat may be affected more by calcium intake than subcutaneous fat.

Two underlying mechanisms may explain the complex effects of calcium on obese mice, the first of which is an increase in defecation. As in the case of magnesium oxide, used to treat constipation in clinical settings, this may be due to increases in moisture content and the amount of feces. Furthermore, previous studies identified obesity as a risk factor for functional defecation disorders, particularly in children $(15,16)$. Thus, it is speculated that reducing obesity of the KK- $A^{y}$ mice may also increase the amount of feces.

The other potential mechanism is calcium-induced reductions in insulin secretion. The present results revealed that serum insulin levels in $\mathrm{KK}-A^{y}$ mice fed the high-calcium diet as well as secretion of insulin by HIT-T15 Langerhans beta cells treated with calcium were decreased. Insulin plays a pivotal role in the storage of energy (triglycerides) in adipocytes. Thus, reductions in serum insulin levels inhibit the hypertrophy of adipocytes, thereby preventing increases in visceral and subcutaneous fat volumes. Of course, there is a possibility that the reduced adiposity led to an improvement in insulin sensitivity and a corresponding decrease in insulin. Thus, additional studies need to be performed to clarify this issue.

Of note, the absorption of calcium was inversely correlated with the chain length of fatty acids due to the formation of calcium soap (17). Thus, it is possible that the formation of calcium soap could inhibit fatty acid absorption. However, soap formation does not take place when fats are given in the form of triglycerides (17). If calcium soap was formed and added into feces, it could explain the inhibition on fat accumulation. A limitation of our study is that we did not show the concentration of lipids in feces.

On the other hand, when the energy storage function of adipocytes is suppressed by calcium, serum blood glucose and lipid levels may increase, as was observed in the present study. This may exacerbate diabetes mellitus type 2 . However, this could be controlled by adjusting total dietary energy intake in daily life. 


\section{A Phylum}

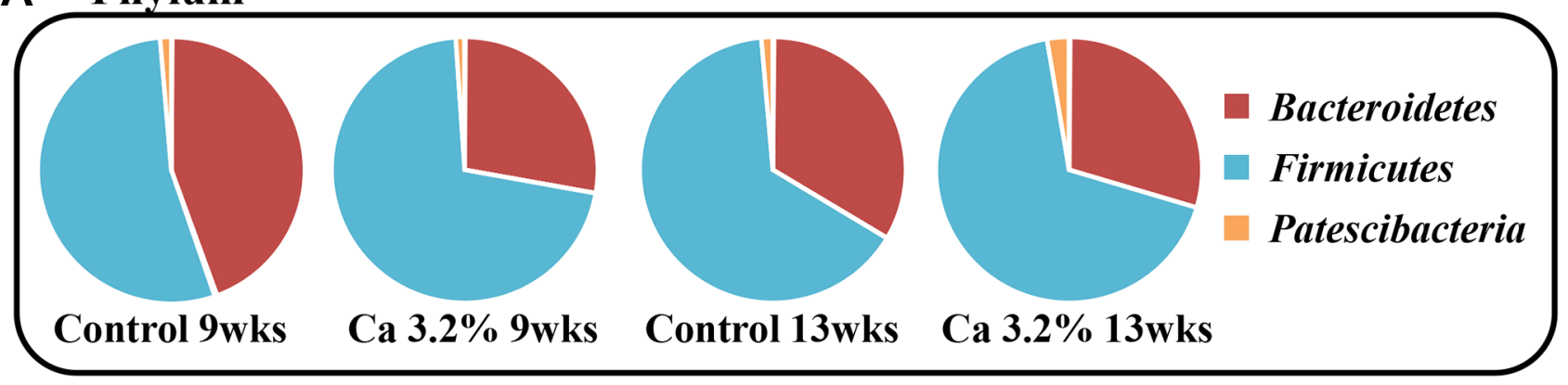

\section{B Class in firmicutes}

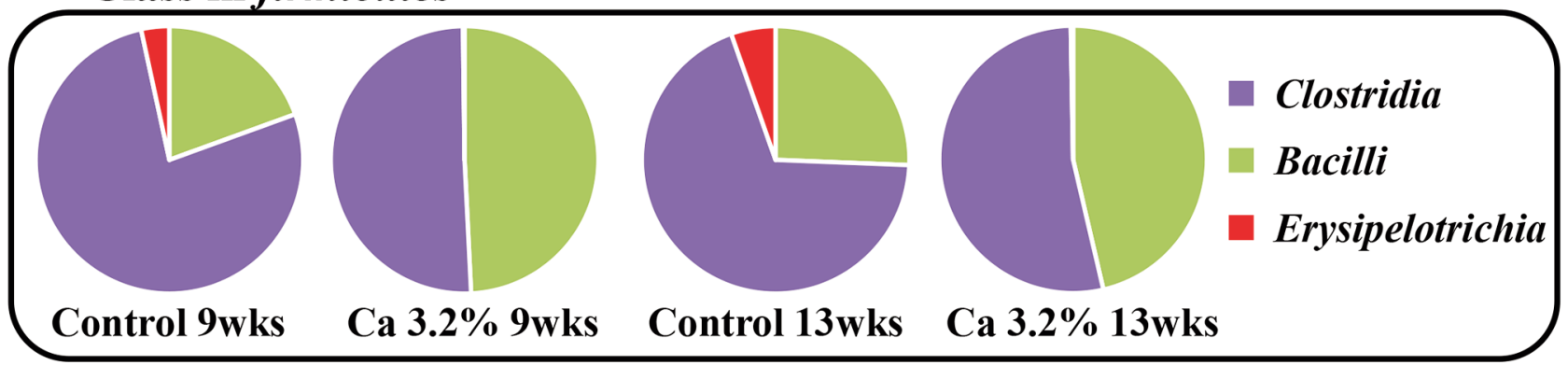

\section{Order in Clostridia}

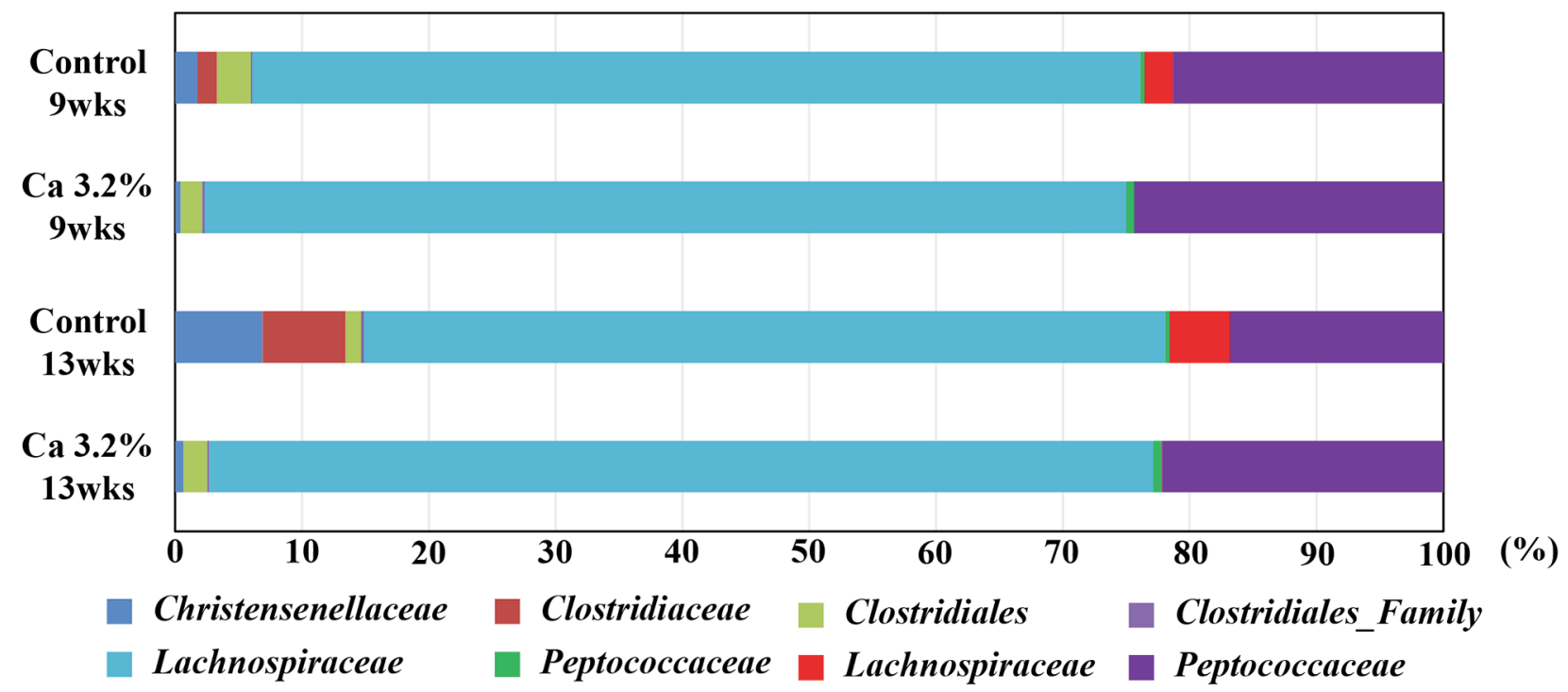

Figure 3. Disappearance of Clostridiaceae in feces by the high-calcium treatment. The intestinal flora of KK-Ay mice at 9 and 13 weeks in the $0.4 \%$ (control) and 3.2\% calcium diet groups were investigated using 16s rRNA sequencing analysis. The intestinal bacteria profile at (A) phylum, (B) class firmicutes, $(C)$ order Clostridia. The raw data are listed in Table IV.

The mechanisms by which calcium decreased insulin levels were not investigated in the present study. Increases in the levels of calcitriol, which is produced in response to a low calcium diet, have been shown to stimulate the influx of calcium into adipocytes, enhance insulin secretion, and promote obesity $(18,19)$. Thus, the decreases observed in insulin levels in mice fed the high-calcium diet may be attributed to the inhibition of calcium influx. Further studies are needed to identify the molecules regulating insulin synthesis by calcium. 
Table IV. Proportional composition of the gut bacteria in KK-A $A^{y}$ mice feces (\%).

\begin{tabular}{|c|c|c|c|c|c|c|c|}
\hline Phylum & Class & Order & Family & $\begin{array}{c}\text { Control }(0.4 \%) \\
9 \mathrm{wks}\end{array}$ & $\begin{array}{l}3.2 \% \\
9 \mathrm{wks}\end{array}$ & $\begin{array}{c}\text { Control }(0.4 \%) \\
13 \text { wks }\end{array}$ & $\begin{array}{c}3.2 \% \\
13 \mathrm{wks}\end{array}$ \\
\hline \multirow[t]{4}{*}{ Actinobacteria } & Actinobacteria & Corynebacteriales & Corynebacteriaceae & 0.000 & 0.001 & 0.001 & 0.002 \\
\hline & & Micrococcales & Dermatophilaceae & 0.000 & 0.000 & 0.000 & 0.000 \\
\hline & Coriobacteriia & Coriobacteriales & Atopobiaceae & 0.000 & 0.000 & 0.000 & 0.000 \\
\hline & & & Eggerthellaceae & 0.108 & 0.090 & 0.157 & 0.134 \\
\hline \multirow[t]{8}{*}{ Bacteroidetes } & Bacteroidia & Bacteroidales & Bacteroidaceae & 31.051 & 19.068 & 20.210 & 20.389 \\
\hline & & & Chitinophagaceae & 0.000 & 0.001 & 0.000 & 0.000 \\
\hline & & & Dysgonomonadaceae & 0.013 & 0.008 & 0.009 & 0.006 \\
\hline & & & Muribaculaceae & 7.952 & 5.349 & 4.387 & 4.088 \\
\hline & & & Prevotellaceae & 4.393 & 1.406 & 8.525 & 3.104 \\
\hline & & & Rikenellaceae & 1.491 & 1.952 & 1.353 & 1.991 \\
\hline & & Chitinophagales & Tannerellaceae & 0.000 & 0.001 & 0.000 & 0.000 \\
\hline & & Flavobacteriales & Weeksellaceae & 0.001 & 0.000 & 0.000 & 0.000 \\
\hline Chloroflexi & Anaerolineae & SBR1031 & $\mathrm{A} 4 \mathrm{~b}$ & 0.000 & 0.001 & 0.000 & 0.000 \\
\hline Deferribacteres & Deferribacteres & Deferribacterales & Deferribacteraceae & 0.286 & 0.021 & 0.047 & 0.004 \\
\hline \multirow[t]{19}{*}{ Firmicutes } & Bacilli & Bacillales & Aerococcaceae & 0.000 & 0.000 & 0.011 & 0.000 \\
\hline & & & Carnobacteriaceae & 0.000 & 0.000 & 0.001 & 0.000 \\
\hline & & & Enterococcaceae & 0.038 & 4.517 & 1.241 & 11.809 \\
\hline & & Lactobacillales & Lactobacillaceae & 8.210 & 23.630 & 13.006 & 15.341 \\
\hline & & & Planococcaceae & 0.000 & 0.001 & 0.000 & 0.004 \\
\hline & & & Staphylococcaceae & 0.001 & 4.349 & 0.104 & 1.511 \\
\hline & & & Streptococcaceae & 2.372 & 2.590 & 2.828 & 2.876 \\
\hline & Clostridia & Clostridiales & Christensenellaceae & 0.740 & 0.156 & 3.188 & 0.233 \\
\hline & & & Clostridiaceae & 0.646 & 0.000 & 3.039 & 0.000 \\
\hline & & & Clostridiales & 1.130 & 0.606 & 0.557 & 0.676 \\
\hline & & & Clostridiales_Family & 0.042 & 0.073 & 0.105 & 0.064 \\
\hline & & & Defluviitaleaceae & 0.000 & 0.000 & 0.000 & 0.001 \\
\hline & & & Eubacteriaceae & 0.000 & 0.000 & 0.001 & 0.001 \\
\hline & & & Lachnospiraceae & 29.492 & 26.217 & 29.238 & 27.036 \\
\hline & & & Peptococcaceae & 0.147 & 0.221 & 0.162 & 0.242 \\
\hline & & & Peptostreptococcaceae & 0.943 & 0.001 & 2.213 & 0.015 \\
\hline & & & Ruminococcaceae & 8.978 & 8.794 & 7.781 & 8.045 \\
\hline & Erysipelotrichia & Erysipelotrichales & Erysipelotrichaceae & 1.855 & 0.135 & 3.615 & 0.185 \\
\hline & Negativicutes & Selenomonadales & Acidaminococcaceae & 0.001 & 0.000 & 0.000 & 0.000 \\
\hline \multirow[t]{11}{*}{ Patescibacteria } & Alphaproteobacteria & Alteromonadales & Pseudoalteromonadaceae & 0.000 & 0.000 & 0.000 & 0.000 \\
\hline & & Betaproteobacteriales & Burkholderiaceae & 0.000 & 0.000 & 0.000 & 0.000 \\
\hline & & & Nitrosomonadaceae & 0.000 & 0.000 & 0.000 & 0.000 \\
\hline & Gammaproteobacteria & Betaproteobacteriales & Burkholderiaceae & 0.000 & 0.000 & 0.001 & 0.000 \\
\hline & & Enterobacteriales & Enterobacteriaceae & 0.140 & 0.544 & 1.086 & 1.812 \\
\hline & & Pseudomonadales & Moraxellaceae & 0.001 & 0.000 & 0.000 & 0.000 \\
\hline & & & Pseudomonadaceae & 0.001 & 0.000 & 0.000 & 0.000 \\
\hline & & Rhodobacterales & Rhodobacteraceae & 0.469 & 0.047 & 0.169 & 0.046 \\
\hline & & & uncultured & 0.611 & 0.266 & 0.173 & 0.430 \\
\hline & & Saccharimonadales & Saccharimonadaceae & 0.142 & 0.219 & 0.004 & 0.384 \\
\hline & Saccharimonadia & Sphingomonadales & Sphingomonadaceae & 0.001 & 0.000 & 0.000 & 0.001 \\
\hline Tenericutes & Mollicutes & Mollicutes & Mollicutes & 0.004 & 0.001 & 0.001 & 0.002 \\
\hline Verrucomicrobia & Verrucomicrobiae & Verrucomicrobiales & Akkermansiaceae & 0.003 & 0.001 & 0.001 & 0.001 \\
\hline
\end{tabular}

Obesity is associated with increases in the number of DCAproducing intestinal bacteria (20). Therefore, we measured fecal DCA levels. DCA is a secondary bile acid produced from primary bile acids by intestinal bacteria. It has been shown to induce DNA damage and enhance intestinal carcinogenesis $(21,22)$. We hypothesized that the attenuation of obesity may decrease the number of DCA-producing bacteria, and, thus, investigated changes in the intestinal flora. As expected, fecal
DCA levels were lower in calcium-treated mice than in control mice. Moreover, the ratio of DCA-producing bacteria in the microflora was reduced. The increase in defecation by calcium intake may also have some role on the reduced fecal DCA levels. Further studies are also needed to clarify the effects of calcium on DCA-producing bacteria.

In conclusion, we herein demonstrated the complex effects of dietary calcium in obese mice, which may be attributed to 
increased defecation and the inhibition of insulin secretion by calcium intake. The present results suggest the potential of calcium as a chemopreventive agent against obesityassociated cancers, such as colorectal cancer.

\section{Conflicts of Interest}

The Authors have no conflicts of interest to declare in relation to this study.

\section{Authors' Contributions}

MT, TH, TN, GF, KM and YM contributed to cell and animal experiments, and data analysis. MK was involved in the literature search. MT and MM planed this work and wrote the paper. MT, TN, $\mathrm{YT}, \mathrm{MH}, \mathrm{KT}$ were responsible for data analysis and the interpretation of results. All Authors read and approved the final draft.

\section{Acknowledgements}

The Authors thank Ms. Ruri Nakanishi and Mr. Naoaki Uchiya, a member of the National Cancer Center Research Core Facility, for their expert technical assistance with animal experiments.

\section{References}

1 Global status report on noncommunicable diseases 2014, World Health Organization. Available at: https://apps.who.int/iris/ bitstream/handle/10665/148114/9789241564854_eng.pdf?sequen ce $=1$ [Last accessed on December 2, 2020]

2 Mandviwala $T$, Khalid $U$ and Deswal A: Obesity and cardiovascular disease: a risk factor or a risk marker? Curr Atheroscler Rep 18(5): 21, 2016. PMID: 26973130. DOI: 10.1007/s11883-016-0575-4

3 Fletcher B, Gulanick M and Lamendola C: Risk factors for type 2 diabetes mellitus. J Cardiovasc Nurs 16(2): 17-23, 2002. PMID: 11800065. DOI: 10.1097/00005082-200201000-00003

4 De Pergola G and Silvestris F: Obesity as a major risk factor for cancer. J Obes 2013: 291546, 2013. PMID: 24073332. DOI: $10.1155 / 2013 / 291546$

5 Teraoka N, Mutoh M, Takasu S, Ueno T, Nakano K, Takahashi M, Imai T, Masuda S, Sugimura T and Wakabayashi K: High susceptibility to azoxymethane-induced colorectal carcinogenesis in obese KK-Ay mice. Int J Cancer 129(3): 528-535, 2011. PMID: 20886595. DOI: $10.1002 / \mathrm{ijc} .25711$

6 Yamaji T, Iwasaki M, Sasazuki S, Kurahashi N, Mutoh M, Yamamoto S, Suzuki M, Moriyama N, Wakabayashi K and Tsugane S: Visceral fat volume and the prevalence of colorectal adenoma. Am J Epidemiol 170(12): 1502-1511, 2009. PMID: 19923108. DOI: 10.1093/aje/kwp311

7 Ishino K, Mutoh M, Totsuka Y and Nakagama H: Metabolic syndrome: a novel high-risk state for colorectal cancer. Cancer Lett 334(1): 56-61, 2013. PMID: 23085010. DOI: $10.1016 /$ j.canlet.2012.10.012

8 Loos RJ, Rankinen T, Leon AS, Skinner JS, Wilmore JH, Rao DC and Bouchard C: Calcium intake is associated with adiposity in Black and White men and White women of the HERITAGE Family Study. J Nutr 134(7): 1772-1778, 2004. PMID: 15226468. DOI: $10.1093 /$ jn/134.7.1772
9 Davies KM, Heaney RP, Recker RR, Lappe JM, Barger-Lux MJ, Rafferty $\mathrm{K}$ and Hinders S: Calcium intake and body weight. J Clin Endocrinol Metab 85(12): 4635-4638, 2000. PMID: 11134120. DOI: $10.1210 /$ jcem.85.12.7063

10 Kondo K, Nozawa K and Romida T: Inbred strains resulting from Japanese mice. Bull Exp Anim 6: 107-112, 1957.

11 Nakamura M and Yamada K: Studies on a diabetic (KK) strain of the mouse. Diabetologia 3(2): 212-221, 1967. PMID: 4907141. DOI: $10.1007 / B F 01222198$

12 Hagio M, Matsumoto $M$ and Ishizuka S: Bile acid analysis in various biological samples using ultra performance liquid chromatography/electrospray ionization-mass spectrometry (UPLC/ESI-MS). Methods Mol Biol 708: 119-129, 2011. PMID: 21207286. DOI: 10.1007/978-1-61737-985-7_6

13 Scheuer SH, Færch K, Philipsen A, Jørgensen ME, Johansen NB, Carstensen B, Witte DR, Andersen I, Lauritzen T and Andersen GS: Abdominal fat distribution and cardiovascular risk in men and women with different levels of glucose tolerance. J Clin Endocrinol Metab 100(9): 3340-3347, 2015. PMID: 26120787. DOI: $10.1210 /$ JC.2014-4479

14 Vissers D, Hens W, Taeymans J, Baeyens JP, Poortmans J and Van Gaal L: The effect of exercise on visceral adipose tissue in overweight adults: a systematic review and meta-analysis. PLoS One 8(2): e56415, 2013. PMID: 23409182. DOI: 10.1371/ journal.pone.0056415

15 Kavehmanesh Z, Saburi A and Maavaiyan A: Comparison of body mass index on children with functional constipation and healthy controls. J Family Med Prim Care 2(3): 222-226, 2013. PMID: 24479087. DOI: 10.4103/2249-4863.120715

16 Koppen IJ, Kuizenga-Wessel S, Saps M, Di Lorenzo C, Benninga MA, van Etten-Jamaludin FS and Tabbers MM: Functional defecation disorders and excessive body weight: a systematic review. Pediatrics 138(3): e20161417, 2016. PMID: 27531145. DOI: 10.1542/peds.2016-1417

17 Gacs G and Barltrop D: Significance of Ca-soap formation for calcium absorption in the rat. Gut 18(1): 64-68, 1977. PMID: 838405. DOI: $10.1136 /$ gut.18.1.64

18 Zemel MB: Role of dietary calcium and dairy products in modulating adiposity. Lipids 38(2): 139-146, 2003. PMID: 12733746. DOI: $10.1007 / \mathrm{s} 11745-003-1044-6$

19 Zemel MB, Shi H, Greer B, Dirienzo D and Zemel PC: Regulation of adiposity by dietary calcium. FASEB J 14(9): 1132-1138, 2000. PMID: 10834935.

20 Yoshimoto S, Loo TM, Atarashi K, Kanda H, Sato S, Oyadomari S, Iwakura Y, Oshima K, Morita H, Hattori M, Honda K, Ishikawa Y, Hara E and Ohtani N: Obesity-induced gut microbial metabolite promotes liver cancer through senescence secretome. Nature 499(7456): 97-101, 2013. PMID: 23803760. DOI: $10.1038 /$ nature 12347

21 Bernstein H, Bernstein C, Payne CM and Dvorak K: Bile acids as endogenous etiologic agents in gastrointestinal cancer. World J Gastroenterol 15(27): 3329-3340, 2009. PMID: 19610133. DOI: $10.3748 /$ wjg. 15.3329

22 Suzuki K and Bruce WR: Increase by deoxycholic acid of the colonic nuclear damage induced by known carcinogens in C57BL/6J mice. J Natl Cancer Inst 76(6): 1129-1132, 1986. PMID: 3458949

Received March 30, 2021

Revised April 30, 2021

Accepted May 4, 2021 